\title{
Enhanced Milk-Clotting Enzyme Production of Mucor Miehei Mutated by UV and LiCl
}

\author{
Wei-bing ZHANG ${ }^{1,2}$, Zhong-ming ZHANG $^{1}$ and Tuo $\mathrm{YAO}^{2, *}$ \\ ${ }^{1}$ College of Food Science and Technology Engineering, Gansu Agricultural \\ University, Lanzhou 730070, China \\ ${ }^{2}$ College of Pratacultural Science, Gansu Agricultural University, Lanzhou 730070, \\ China \\ ${ }^{*}$ Corresponding author
}

Keywords: Milk-clotting enzyme, Mucor miehei, Mutation.

\begin{abstract}
Milk clotting enzyme is an important enzyme in cheese industry, to obtain an industrial strain with high milk-clotting enzyme activity, Mucor miehei was used as the origin strain and mutagenized by Ultraviolet (UV) and UV combining lithium chloride(LiCl), respectively. The result shows that lower concentrations of $\mathrm{LiCl}$ can increase the survival rate of the spores treated with UV, while higher concentration of $\mathrm{LiCl}$ can increase the mortality of the spores treated with UV. The highest positive rate (reached $32.17 \%$ ) was achieved in the compound mutation, which was higher than that of the UV mutagenesis $(21.45 \%)$. On the basis of multiple mutation, a mutant UV-LiCl-6 was screened. The milk-clotting activity of UV-LiCl-6 reached $2703.58 \mathrm{SU} / \mathrm{mL}$ and was $57.70 \%$ higher than that of the parent strain. Results of the pass-generation test indicated that the strain had good genetic stability and may be ideal strains for the production of milk-clotting enzyme. Additionally, it was demonstrated that compound mutagenesis with $\mathrm{UV}$ and $\mathrm{LiCl}$ is an effective mutation method for the breeding of enzyme-producing strains.
\end{abstract}

\section{Introduction}

Milk clotting enzyme is a key enzyme in cheese industry[1], which can cause milk proteins to curdle by selectively breaking up peptide bonds between certain amino acids within the Kappa casein chain[2]. Milk clotting enzyme not only clots the milk but also play an important role during cheese maturation, which is a vital and complex process for the balanced development of flavour and texture[3]. The cheese industry has traditionally used calf rennet for clotting milk - the first step in cheese making[4]. The worldwide increase of cheese production and the reduced supply of calf rennet have led to a search for novel sources of rennet. [5]. Attention has been focused on the production of milk-clotting enzyme from microbial sources for use as rennet substitutes[6], because its production is cheaper, biochemical diversity is greater, shorter fermentation period and genetic modification is easier[7]. Most commercial milk clotting enzyme are produced from Mucor pusillus, Mucor miehei and Endothia parasitica[8].

Many research studies on the enhancement of milk-clotting enzyme production have been reported in recent years, most of them dealt with the screening of wild strains and the influence of the fermentation conditions[9]. However, there are few reports about mutagenesis programs for screening milk-clotting enzyme overproducing mutants. Compound mutagenesis of UV and $\mathrm{LiCl}$ is easy and simple to handle and has been successfully applied in breeding of 
mutants with improved properties [10]. There are no reports about mutagenesis for screening of mutants with high activity milk-clotting enzyme using this method. In the present study, compound mutagenesis of $\mathrm{UV}$ and $\mathrm{LiCl}$ was performed to improve the yield of milk-clotting enzyme from Mucor miehei. In addition, the parameters of compound mutagenesis of UV and $\mathrm{LiCl}$ and characteristics of the mutant were studied.

\section{Materials and Methods}

\section{Microorganism and Medium}

The microorganism employed in this study was Mucor miehei HL-1 gifted by GanSu HuaLing Biological Technology Co. Ltd.

Potato dextrose agar (PDA) slants were used for sporulation and storage.

Solid state fermentation medium: $10 \mathrm{~g}$ wheat bran was taken in $250 \mathrm{~mL}$ conical flask and moistened with $10 \mathrm{~mL}$ distilled water containing $2.5 \%$ glucose $(\mathrm{w} / \mathrm{w}), 1.0 \% \mathrm{NH} 4 \mathrm{NO} 3(\mathrm{w} / \mathrm{w})$, $1.5 \%$ whey powder $(\mathrm{w} / \mathrm{w})$. The $\mathrm{pH}$ of the medium was ajusted to 6.0 .

\section{Mutation with UV Treatment}

The time of UV irradiation was designed at 30, 60, 90, 120, 150, 180, 210 and 240 seconds, respectively. The lethality rates and the positive mutation rate calculated by using a method of Zhang et al [11].

\section{Compound Mutation of UV and LiCl}

The method of compound mutation of UV and LiCl was employed by using a modified method of Zhang et al [11]. The concentration of $\mathrm{LiCl}$ was designed as $0.5 \%, 1 \%, 1.5 \%, 2 \%$ and $2.5 \%$.

\section{Hereditary Stability of Mutant Strains}

The genetic stability of milk-clotting enzyme producing strains was determined by continuous passage experiment. Following culture on PDA slants at $30{ }^{\circ} \mathrm{C}$ for $4-5$ days of mutant isolate was transferred to solid state fermentation in static cultivation at $30{ }^{\circ} \mathrm{C}$ for 4 days; then the milk-clotting enzyme activity of the supernatant was tested. This process was repeated 8 times.

\section{Milk-clotting Activity Determination}

The milk-clotting activity was determined as described by Arima and Iwasake[12].

\section{Proteolytic Activity Determination}

The proteolytic activity of the enzyme was assayed as modified Anson's method[12].

\section{Results and Discussion}

\section{Optimum Parameter Determination of UV}

The lethality rates and positive mutation rates appeared to correlate with the irradiation time of UV. The effects of UV irradiation to strain HL-1 on the lethality rates and the positive mutation rates are shown in Fig 1. 
It indicated that the lethality rate increased along with the UV irradiation time increased from 30 to 240 seconds. With 30 seconds of exposure to UV, the lethality rate of Mucor miehei was $32.14 \%$, and after 240 seconds it was $100 \%$. The positive mutation rate had a close relationship with the lethality rate. The distribution of the positive mutation rate was shown in Fig. 1. The highest positive mutation rate (reached 21.45\%) was achieved, when the UV irradiation time was 90 seconds and the lethality rate was $78.57 \%$. This fact confirmed the theory that the highest positive mutation rate was obtained when the lethality rate of the microorganism ranges from $70 \%$ to $80 \%$ [11]. Hence, the UV irradiation time of 90 seconds was chosen as the optimum parameter of UV mutagenesis in the follow experiments.

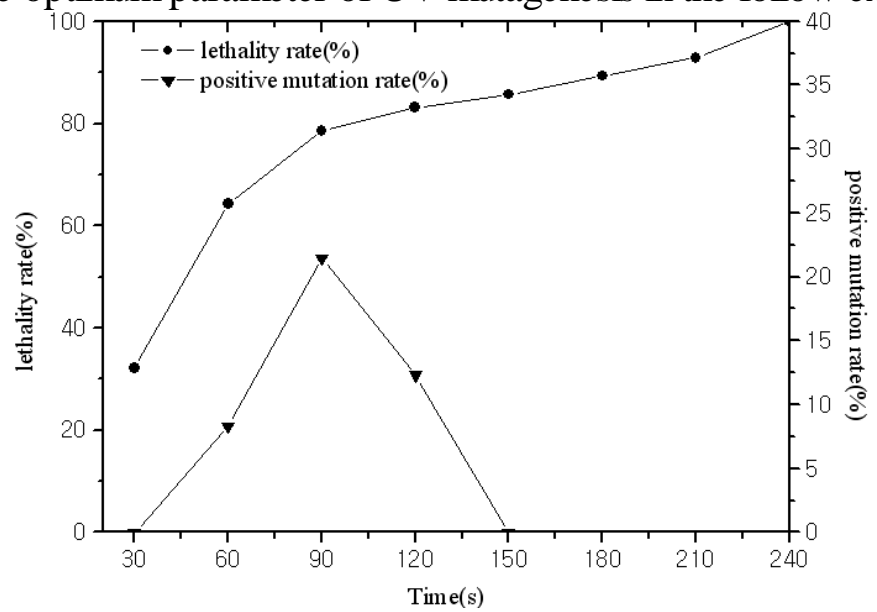

Fig.1 The lethality rate $(\bullet)$ and positive mutation rate $(\boldsymbol{\nabla})$ of Mucor miehei spores of UV treatment.

\section{Screening Result of UV Treatment}

Five mutants with high milk-clotting activity were isolated and inoculated into solid state fermentation medium after Mucor miehei (HL-1) spores were treated with UV repeatedly. Table 1 showed milk-clotting activity of five mutants obtained in primary screening. The high milk-clotting activity mutant, UV-13, the milk-clotting activity was about $42.85 \%$ higher than that of the origin strain, while the proteolytic activity reduced by $13.66 \%$. The ratio of milk-clotting activity to proteolytic activity reached 271.11 .

Table 1 The Screening Results of UV Treatment

\begin{tabular}{cccc}
\hline Strains & $\begin{array}{c}\text { Milk-clotting } \\
\text { Activity(SU/mL) }\end{array}$ & $\begin{array}{c}\text { Proteolytic } \\
\text { activity(U/mL) }\end{array}$ & MCA/PA \\
\hline HL-1 & 1714.28 & 10.54 & 162.60 \\
UV-2 & 2099.73 & 9.88 & 214.61 \\
UV-13 & 2448.98 & 9.10 & 271.11 \\
UV-19 & 2123.89 & 9.64 & 220.36 \\
UV-20 & 2195.79 & 8.67 & 254.06 \\
UV-31 & 2228.41 & 8.32 & 268.09 \\
\hline
\end{tabular}

\section{Optimum Parameter Determination of Multiple Mutated By UV and LiCl}

Fig. 2 showed that the lethality rate of the spores appeared to correlate with the different $\mathrm{LiCl}$ concentrations between 0.5 and $3 \%(\mathrm{w} / \mathrm{v})$. When the concentration of LiClincreased from 0.5 to $1 \%$, the lethality rate increased from 34.48 to $65.52 \%$, implying that lower concentrations of LiCl can increase the survival rate of the spores treated with UV. When the concentration of 
LiCl increased from 1.5 to $2.5 \%$, the lethality rate increased from 82.76 to $93.10 \%$, indicating that higher concentration of $\mathrm{LiCl}$ can increase the mortality of the spores treated with UV.

The relationship between the positive mutation rate and the concentration of $\mathrm{LiCl}$ was shown in Fig.2. It revealed that the positive mutation rate increased sharply along with the concentration of $\mathrm{LiCl}$ increased from $0.5 \%$ to $1.5 \%$. When the concentration of $\mathrm{LiCl}$ was $1.5 \%$, the highest positive rate (reached $32.17 \%$ ) was achieved, which was higher than the highest positive mutation rate of the spores treated with UV $(21.45 \%)$. When the concentration of $\mathrm{LiCl}$ increased from 1.5 to $2.5 \%$, the positive mutation rate decreased from $32.17 \%$ to 0 . In the next step, the $\mathrm{LiCl}$ concentration of $1.5 \%$ was chosen as the optimum mutagenic agent dose for $\mathrm{UV}$ and $\mathrm{LiCl}$ treatment.

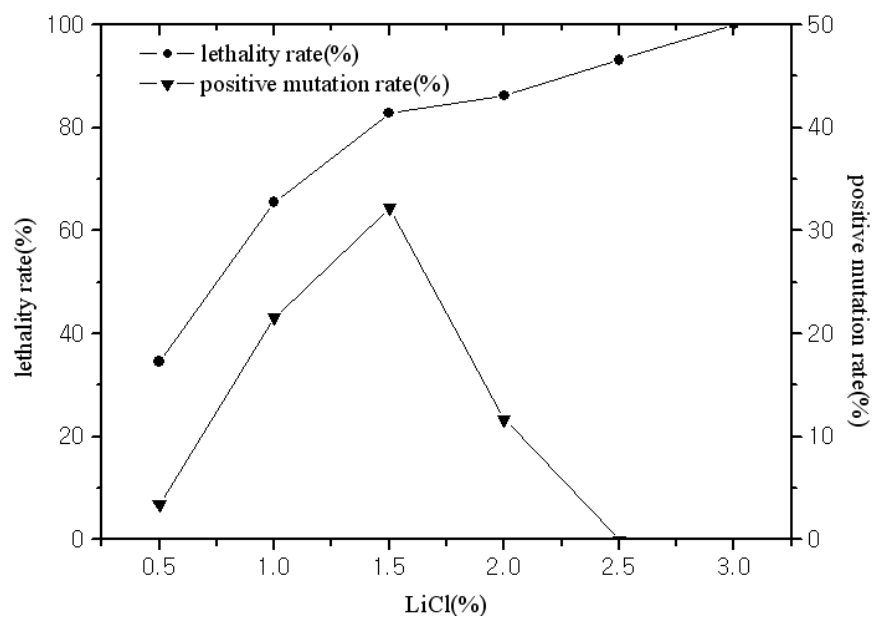

Fig.2 The lethality rate $(\bullet)$ and positive mutation rate $(\boldsymbol{\nabla})$ of Mucor miehei spores after multiplemutation by $\mathrm{UV}$ and $\mathrm{LiCl}$.

\section{Screening Result of Multiple Mutated by UV and LiCl}

After Mucor miehei (HL-1) spores were multiple mutated by UV and LiCl repeatedly, seven mutants with high milk-clotting activity were isolated. Table 2 showed milk-clotting activity of seven mutants obtained in primary screening. Among them, mutant UV-LiCl-6 with the milk-clotting activity of $2703.58 \mathrm{SU} / \mathrm{mL}$, exhibited about $57.70 \%$ increase in enzyme activity compared with that of the origin strain, while the proteolytic activity reduced by $27.80 \%$. The ratio of milk-clotting activity to proteolytic activity reached 355.06. Thus, the mutant UV-LiCl-6 was selected as a preferable milk-clotting enzyme producer for further studies.

Table 2 The Screening Results of Compound Mutagenesis by UV and $\mathrm{LiCl}$

\begin{tabular}{cccc}
\hline Strains & $\begin{array}{c}\text { Milk-clotting } \\
\text { Activity(SU/mL) }\end{array}$ & $\begin{array}{c}\text { Proteolytic } \\
\text { activity(U/mL) }\end{array}$ & MCA/PA \\
\hline HL-1 & 1714.28 & 10.54 & 162.60 \\
UV-LiCl-6 & 2703.58 & 7.61 & 355.06 \\
UV-LiCl-7 & 2535.27 & 8.43 & 300.59 \\
UV-LiCl-11 & 2687.98 & 7.65 & 351.21 \\
UV-LiCl-14 & 2639.28 & 7.89 & 334.61 \\
UV-LiCl-17 & 2554.93 & 7.69 & 332.13 \\
UV-LiCl-20 & 2688.47 & 8.32 & 323.24 \\
UV-LiCl-21 & 2610.16 & 7.58 & 344.56 \\
\hline
\end{tabular}




\section{Hereditary Stability of Mutant Strains}

The stability of mutants is very important in industrial practice. To estimate the feasibility of this mutation for industrial application, the genetic stability of mutant UV-LiCl-6 was also investigated. After 8 generations, the milk-clotting activity of the mutant UV-LiCl-6 kept at 2711.16 SU/mL, indicating a weak influence of passage times on enzyme production of the mutant UV-LiCl-6. The average milk-clotting enzyme activity of mutant UV-LiCl-6 for 8 generations are listed in Table 3. The results indicated that the genetic stability of the mutant UV-LiCl-6 could satisfy the requirement of industrial application.

Table 3 Milk-clotting Activity of Mutant UV-LiCl-6 for Eight Generations.

\begin{tabular}{ccccccccc}
\hline Passage times & 1 & 2 & 3 & 4 & 5 & 6 & 7 & 8 \\
\hline $\begin{array}{c}\text { milk-clotting } \\
\text { activity }(\mathrm{SU} / \mathrm{mL})\end{array}$ & 2711.10 & 2711.11 & 2711.61 & 2711.46 & 2711.32 & 2711.81 & 2712.08 & 2711.16 \\
\hline
\end{tabular}

\section{Effect of Fermentation Time on the Production of Milk-clotting Enzyme}

The time course of production of wild strain HL-1 and mutant UV-LiCl-6 for a period of 120 hours is shown in Fig.3.

In general, changes of milk-clotting activity of mutant showed the time is difference that reaches the highest enzyme activity as that of wild strain. The mutant UV-LiCl-6 began to produce milk-clotting enzyme for 48 hours. Milk-clotting activity of the mutant UV-LiCl-6 increased sharply from the 60 hours of fermentation, reached the maximum of 2706.32 $\mathrm{SU} / \mathrm{mL}$ after 96 hours of fermentation, then the level of milk-clotting activity decreased in the further fermentation process. The wild strain began to produce milk-clotting enzyme for 60 hours, milk-clotting activity increased from the 72 hours, reached the maximum of 1720.21 SU/mL after 108 hours of fermentation. Results show that the mutant UV-LiCl-6 maintained a high capacity for the product milk-clotting enzyme.

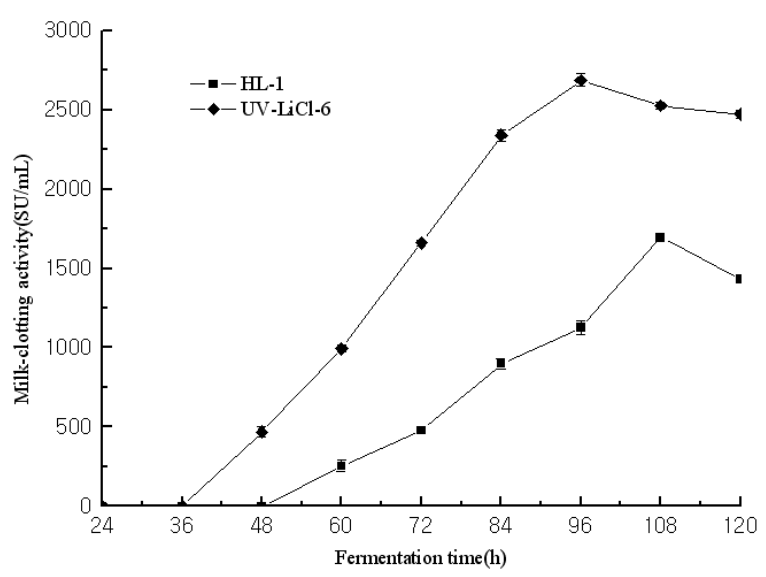

Fig.3 Time course of milk clotting enzyme production by HL-1 $(\bullet)$ and UV-LiCl-6 ( $\bullet$ ).

\section{Conclusion}

The research indicated that multiple mutation with optimum 90 seconds UV and the $\mathrm{LiCl}$ concentration of $1.5 \%$, the mutant strain UV-LiCl-6 was screened. The activity of milk-clotting enzyme by the mutant strain UV-LiCl-6 reached a level of $2703.58 \mathrm{SU} / \mathrm{mL}$, which was $57.70 \%$ higher than that of the wild strain, while the proteolytic activity reduced by 
$27.80 \%$. The ratio of milk-clotting activity to proteolytic activity reached 355.06 . The mutant was very stable and has potential application for milk-clotting enzyme production.

\section{Acknowledgement}

The authors are grateful to the Agricultural Scientific and Technological Innovation Project of Gansu Province, China (GNCX-2014-31) for financial support of this work.

\section{References}

[1] Abbas, H.M.; Foda, M.S.; Kassem, J.M.; Bayomi, H.M. and Moharam, M.E. Production of White Soft Cheese Using Fungal Coagulant Produced by Solid State Fermentation Technique. World Applied Sciences Journal. 2013, 25, 939-944.

[2] Ageitos, J.M.; Vallejo, J.A.; Sestelo, A.B.; Poza, M. And Villa, T.G. Purification and characterization of a milk-clotting protease from Bacillus licheniformisstrain USC13.Journal of Applied Microbiology. 2007, 103, 2205-2213.

[3] Kumar, S.; Sharma, N.S.; Saharan, M.R.; Singh, R. Extracellular acid protease from Rhizopus oryzae: purification and characterization. Process Biochemistry. 2005, 40, 1701-1705.

[4] Vishwanatha, K.S.; Appurao, A.G.; Singh, S.A. Production and characterization of a milk-clotting enzyme from Aspergillus oryzae MTCC 5341. Applied Microbiology and Biotechnology. 2010, 85, 1849-1859.

[5] Wu, F.C.; Chang, C.W.; Shih, I.L. Optimization of the production and characterization of milk clotting enzymes by Bacillus subtilis natto. Springer plus. 2013, 2, 33.

[6] Hashem, A.M. Purication and properties of a milk-clotting enzyme produced by Penicillium oxalicum. Bioresource Technology. 2000, 75, 219-222.

[7] El-Bendary, M.A.; Maysa, E.M.; Thanaa, H.A. Purification and Characterization of Milk Clotting Enzyme Produced by Bacillus sphaericus. Journal of Applied Sciences Research. 2007, 3, 695-699.

[8] Silveira, G.G.; Oliveira, G.M.; Monti, E.J.; Contiero, J. Microbial Rennet Produced by Mucor miehei in Solid-State and Submerged Fermentation. Brazilian Archives of Biology and Technology. 2005, 48, 931-937.

[9] Ataci, N.; Simsek, G.; Atac, I.A.; Kuzu,H. Temperature and pH Effect on Milk Clotting Time of Mucor miehei Rennet. Asian Journal of Chemistry. 2009, 21,1754-1758.

[10]Zhu, G.S; .Liu, Z.Y.; Lei, B.X;. Liao, G.H. Selection of high-yielding strains of Mortierella producingy-linolenic acid by UV and LiCl. Mycosystema. 2005, 24, 85-92. (In Chinese)

[11]ZHANG, W. B.; LIU, F. N.; YANG, M.; LIANG, Q.; ZHANG, Y.; AI, D.Y. and AN, Z. G. Enhanced $\beta$-galactosidase production of Aspergillus oryzae mutated by UV and LiCl. Preparative Biochemistry and Biotechnology, Vol. 44, no. 3, p. 310-320.

[12] Arima, K.; Iwasake, K. Milk-clotting enzyme from microorganisms. Part I Screening test and the identification of the potent fungus. Agricultural Biological Chemistry. 1967, 31,540-545. 